\title{
Estudo do reparo ósseo com matriz óssea bovina desvitalizada e calcitonina em ratos $^{1}$
}

\author{
Study of bone repair with bovine bone devitalized matrix and calcitonin in rats
}

\author{
Maria Cristina Pita Sassioto ${ }^{2}$, Celso Massaschi Inouye ${ }^{3}$, Ricardo Dutra Aydos ${ }^{4}$, \\ Arthur Silveira de Figueiredo ${ }^{5}$, Elenir Rose Jardim Cury Pontes ${ }^{6}$, Luiz Carlos Takita ${ }^{7}$
}

1. Trabalho realizado no Departamento de Clínica Cirúrgica da Universidade Federal de Mato Grosso do Sul (UFMS), dentro do Programa de Pós-Graduação em Ciências da Saúde pelo Convênio Universidade de Brasília (UnB) - UFMS Universidade Federal de Goiás (UFG).

2. Médico Especialista, pós-graduando do Programa de Pós-Graduação em Ciências da Saúde pelo convênio UnB-UFMSUFG, Médico Especialista em Ortopedia e Traumatologia, Professor Contratado do Departamento de Clínica Médica da UFMS.

3. Doutor em Medicina, Orientador do Programa de Pós-Graduação em Ciências da Saúde pelo Convênio UnB-UFMS-UFG, Professor Titular do Departamento de Clínica Cirúrgica da UFMS.

4. Doutor em Medicina, Coordenador do Programa de Pós-Graduação em Ciências da Saúde pelo Convênio UnB-UFMSUFG

5. Doutor em Medicina, Chefe de Serviço de Ortopedia e Traumatologia da UFMS.

6. Doutor em Saúde Pública, Professor Visitante do Departamento de Tecnologia de Alimentos e Saúde Pública da UFMS.

7. Médico Especialista, Professor Adjunto do Departamento de Anatomia Patológica da UFMS.

\section{RESUMO}

OBJETIVO: Estudar o efeito da calcitonina no reparo de defeito femoral preenchido com matriz óssea bovina desvitalizada.

MÉTODOS: Quarenta e oito ratos Wistar, machos e adultos foram distribuídos aleatoriamente em dois grupo com 24 animais. Defeitos femorais bilaterais, com 2mm de diâmetro, foram produzidos na diáfise femoral e preenchidos com matriz óssea bovina desvitalizada. O grupo experimento recebeu $0,05 \mathrm{~mL}$ de calcitonina, intramuscular, no pós-operatório imediato; o grupo controle recebeu $0,05 \mathrm{~mL}$ de cloreto de sódio 0,9\%. Os animais foram sacrificados com 7, 14 e 21 dias e os fêmures submetidos a avaliação clínica, microscópica e histométrica. Foram utilizados os testes “t” de Student, Kruskal-Wallis e Mann-Whitney para a análise estatística dos resultados.

RESULTADOS: Os resultados clínicos não mostraram diferença entre os grupos controle e experimento. Microscopicamente, os defeitos mostraram reação inflamatória e formação óssea ativa nas proximidades da matriz óssea bovina. A análise quantitativa mostrou maior formação óssea nas fases iniciais da osteogênese reparadora no grupo experimento $(Z=4,82$ e $Z=4,43)$, sem diferenças em relação à reação inflamatória em ambos grupos.

CONCLUSÃO: O uso de calcitonina em defeitos preenchidos com matriz óssea bovina desvitalizada estimula a neoformação óssea com 7 e 14 dias de pós-operatório, mas não diminui a reação inflamatória.

DESCRITORES: Enxerto autógeno. Osso bovino. Calcitonina. Ratos. 


\section{SUMMARY}

PURPOSE: To study the effect of the calcitonina in the repair of femoral defect fulfilled with bovine bone devitalized matrix and calcitonin in rats.

METHODS: Forty eight adult male Wistar rats were distributed into two group with 24 animals. Bilateral femoral defects with $2 \mathrm{~mm}$ of diameter were produced in the femoral shaft and fulfilled with bovine bone devitalized matrix. The experimental group received calcitonin $0,05 \mathrm{~mL}$ intramuscular, in the immediate postoperative period; the control group received $0,05 \mathrm{~mL}$ of saline solution. The animals were sacrificed with 7, 14 and 21 days and the femurs were submitted the clinical, microscopic and histometric evaluation. The data was submitted a statistical evaluation with Student “t”, Kruskal-Wallis and Mann-Whitney.

RESULTS: The clinical results didn't show difference between the control and experimental groups. In the optical microscopy the defects showed inflammatory reaction and active bony formation in the proximities of the bovine bony fragments. The quantitative analysis showed larger bony formation in the initial phases of the reparative osteogenesis in the experimental group $(Z=4,82$ and $Z=4,43)$, without differences in relation to the inflammatory reaction in both groups.

CONCLUSION: The calcitonina and the fulfillment of defect with bovine bone devitalized matrix enhance bone formation and no decrease inflammatory reaction in the 7 and 14 postoperative period.

KEY WORDS: Autograft. Bovine bone. Calcitonin. Rats.

\section{Introdução}

O reparo de grandes defeitos ósseos continua sendo um desafio aos profissionais da traumatologia, onde os métodos tradicionais de tratamento utilizam o enxerto ósseo autógeno pela sua propriedade osteogênica e facilidade de incorporação em relação aos enxertos homógenos e xenógenos ${ }^{1,2}$.

A aquisição de enxerto ósseo autógeno agrega riscos ao paciente, incluindo incisão cirúrgica adicional, aumento da morbidade pós-operatória, debilitação do local doador e quantidade disponível insatisfatória de enxerto autógeno, como nas crianças e adultos submetidos a procedimentos operatórios anteriores ${ }^{1,2}$.

Os biomateriais inorgânicos são compostos alternativos ao uso de enxertos ósseos autógenos por serem produzidos com propriedades potencialmente semelhantes às do tecido receptor e quando usados em defeitos de ossos longos constituem-se em obstáculo à invasão do tecido mole vizinho, permitindo crescimento de tecido ósseo diretamente sobre suas trabéculas porosas e acelulares ${ }^{3,4}$.

Entre os biomateriais, a matriz inorgânica derivada de osso bovino, uma hidroxiapatita utilizada no preenchimento de cavidades com função de arcabouço para neoformação óssea, pode ser parcial ou completamente removida do local receptor por um lento processo de reabsorção de superfície desencadeando intensa reação inflamatória ${ }^{5,6}$.

A matriz óssea bovina desvitalizada, como todas as modalidades de enxerto, está sujeita a influência de fatores próprios do organismo receptor, como tensão de oxigênio, desnutrição protéica, doenças metabólicas, hormônios e vitaminas, sendo a velocidade da reconstrução óssea relacionada aos níveis de fósforo, cálcio e de calcitonina, um hormônio com ação direta no metabolismo destes minerais e fator de grande importância na recuperação e manutenção da homeostase óssea. Por possuir ação analgésica, antiinflamatória e antiosteoclástica, a calcitonina é utilizada no tratamento de distúrbios clínicos e biológicos caracterizados por excessiva

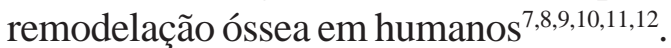

Ziegler e Delling ${ }^{10}$ relataram que a calcitonina promove aceleração do processo regenerativo de defeito ósseo sem enxertia, em ratos. Paavolainen e col. ${ }^{11}$ não encontraram diferenças nos aspectos radiográficos, microscópicos e biomecânicos em fraturas de tíbias de ratos tratados com calcitonina. Guarniero e col..$^{9}$ estudaram a influência da calcitonina e da desnutrição protéica, isoladas e associadas, na resistência mecânica e na rigidez do tecido ósseo em ratos, observando que a calcitonina favoreceu a neoformação óssea, reduzindo a ocorrência de pseudartrose. Canavero e col. ${ }^{12}$ utilizando calcitonina 
no reparo de defeitos ósseos circunscritos em ratos, observaram formação de tecido de granulação infiltrado por células inflamatórias, seguida por diferenciação osteoblástica e formação de trabéculas ósseas.

Considerando-se a possibilidade da calcitonina promover redução da reação inflamatória e aumento da atividade osteoblástica, fez-se estudo morfológico do reparo de defeitos ósseos provocados operatoriamente em fêmur de ratos, preenchidos com matriz óssea bovina desvitalizada utilizando-se calcitonina de salmão.

\section{Métodos}

A proposta deste trabalho foi aprovada pela Comissão de Ética no Uso de Animais da UFMS (37/2002) e todos os procedimentos foram realizados de acordo com o Animal Experimentation Ethics Committee.

Foram utilizados 48 ratos Wistar, machos, adultos, com peso médio de 392g, procedentes do Biotério Central da UFMS, distribuídos em dois grupos com 24 animais: grupo I (experimento) e grupo II (controle). Os animais foram pesados e anestesiados por solução 1:1 de xilazina e quetamina na dosagem de $0,1 \mathrm{~mL} .100 \mathrm{~g}^{-1}$ de peso, por via intramuscular.

Após tricotomia, realizou-se incisão longitudinal de 20mm em face lateral de coxa, divulsão romba da musculatura com exposição da diáfise femoral e confecção de defeito ósseo com broca metálica de $2 \mathrm{~mm}$ de diâmetro acoplada em perfurador elétrico de baixa rotação, interessando córtex lateral e medular óssea, em ambos fêmures.

Os defeitos foram preenchidos com matriz óssea bovina desvitalizada; a aproximação muscular foi realizada com pontos simples de categute simples 30 e a sutura contínua da incisão cutânea com fio monofilamentado de poliamida $4-0$. No pósoperatório imediato aplicou-se $0,05 \mathrm{~mL}$ (2 UI) de calcitonina de salmão nos animais do grupo I e $0,05 \mathrm{~mL}$ de solução de cloreto de sódio 0,9\% nos animais do grupo II, via intramuscular.

Após recuperação anestésica permitiu-se apoio imediato dos membros operados sem nenhum tipo de imobilização externa, sendo os animais mantidos nas gaiolas com água e ração à vontade até o cumprimento dos seguimentos de 7 (subgrupo A),
14 (subgrupo B) e 21 dias (subgrupo C), quando oito animais de cada grupo foram pesados e sacrificados por inalação contínua de éter etílico.

Os fêmures foram dissecados e após análise macroscópica com observação de alteração morfológica da estrutura femoral (fratura, ossificação ectópica e presença do defeito na cortical óssea), ambos fêmures foram fixados em formol tamponado $10 \%$, descalcificados e submetidos a processamento histológico rotineiro no Departamento de Anatomia Patológica Especial da UFMS. Os cortes histológicos foram corados com hematoxilina-eosina e observados por microscopia óptica em relação a neoformação óssea e reação inflamatória. As fotomicrografias obtidas das lâminas histológicas foram submetidas à análise quantitativa dos parâmetros acima mencionados utilizando-se software de análise de imagens por absormetria de cor.

O conjunto de resultados foi submetido à análise estatística pelos testes “ $t$ ” de Student, Mann-Whitney (Z) e análise de variância por postos de KruskalWallis (H)para comparar os 2 grupos de estudo para cada variável e para cada período (7, 14 e 21 dias). O nível de rejeição da hipótese de nulidade foi fixado em $5 \%$ (a $£ 0,05)$.

\section{Resultados}

Todos os animais ganharam peso (Tabela 1) e não ocorreu nenhum óbito durante o experimento. Na análise macroscópica não foi observada a presença de fratura femoral nem de ossificação ectópica. O defeito na cortical óssea manteve-se visível em todos os períodos de seguimento.

Na microscopia óptica, as áreas do defeito em ambos grupos, com sete dias de seguimento, apresentavam-se preenchidas por fragmentos de matriz óssea bovina desvitalizada, estroma conjuntivo com neoformação vascular, ilhas de tecido ósseo neoformado e reação inflamatória com células gigantes multinucleadas em contato com a matriz óssea bovina e dispersas no infiltrado inflamatório (Figura 1, A-B). Uma maior concentração de osteoblastos e neoformação óssea (Tabela 2) foi observada no grupo experimento.

Com quatorze dias, observou-se fragmentos de matriz óssea bovina desvitalizada, estroma conjuntivo e presença de reação inflamatória em ambos grupos (Figura 1, C-D) (Tabela 3). No grupo controle 
TABELA 1 - Peso Animais dos grupos I e II com respectivos subgrupos A, B e C, segundo o peso inicial e final (grama)

\begin{tabular}{|c|c|c|c|c|c|c|c|}
\hline \multicolumn{4}{|c|}{ GRUPOI } & \multicolumn{4}{|c|}{ GRUPOII } \\
\hline SUBGRUPO & inicial & final & variação & SUBGRUPO & inicial & final & variação \\
\hline \multirow{8}{*}{ A } & 352 & 357 & 5 & \multirow{8}{*}{ A } & 390 & 393 & 3 \\
\hline & 395 & 400 & 5 & & 410 & 413 & 3 \\
\hline & 418 & 420 & 2 & & 375 & 380 & 5 \\
\hline & 375 & 380 & 5 & & 390 & 394 & 4 \\
\hline & 361 & 365 & 4 & & 395 & 400 & 5 \\
\hline & 384 & 389 & 5 & & 416 & 420 & 4 \\
\hline & 390 & 393 & 3 & & 385 & 390 & 5 \\
\hline & 450 & 453 & 3 & & 350 & 352 & 2 \\
\hline \multirow{8}{*}{ B } & 415 & 420 & 5 & \multirow{8}{*}{ B } & 350 & 360 & 10 \\
\hline & 401 & 411 & 10 & & 410 & 421 & 11 \\
\hline & 355 & 364 & 9 & & 401 & 409 & 8 \\
\hline & 364 & 372 & 8 & & 395 & 404 & 9 \\
\hline & 370 & 381 & 11 & & 400 & 411 & 11 \\
\hline & 378 & 388 & 10 & & 361 & 371 & 10 \\
\hline & 410 & 420 & 10 & & 370 & 380 & 10 \\
\hline & 355 & 364 & 9 & & 375 & 383 & 8 \\
\hline \multirow{8}{*}{$\mathrm{C}$} & 380 & 400 & 20 & \multirow{8}{*}{$\mathrm{C}$} & 400 & 420 & 20 \\
\hline & 391 & 408 & 17 & & 385 & 402 & 17 \\
\hline & 385 & 400 & 15 & & 378 & 390 & 12 \\
\hline & 386 & 400 & 14 & & 390 & 411 & 21 \\
\hline & 400 & 420 & 20 & & 380 & 401 & 21 \\
\hline & 395 & 409 & 14 & & 380 & 400 & 20 \\
\hline & 375 & 391 & 16 & & 410 & 430 & 20 \\
\hline & 411 & 422 & 11 & & 376 & 390 & 14 \\
\hline Média & 387,3 & 396,96 & 9,63 & Média & 386,33 & 396,88 & 10,54 \\
\hline D.P. & 23,34 & 23,35 & 5,40 & D.P. & 17,94 & 19,38 & 6,34 \\
\hline
\end{tabular}

D.P.: desvio padrão

TABELA 2 - Fêmures dos animais dos grupos I e II com respectivos subgrupos A, B e C, segundo a quantificação de tecido ósseo neoformado (porcentagem)

\begin{tabular}{ccccccc}
\hline & \multicolumn{3}{c}{ GRUPOI } & \multicolumn{3}{c}{ GRUPO II } \\
\hline SUBGRUPO & A & B & C & A & B & C \\
\cline { 2 - 6 } & 33,1 & 47,5 & 59,6 & 21,1 & 45,6 & 60,0 \\
& 32,1 & 46,2 & 58,7 & 14,9 & 42,0 & 61,0 \\
& 31,5 & 48,3 & 59,6 & 15,6 & 45,5 & 58,7 \\
& 32,4 & 45,6 & 58,9 & 17,9 & 45,6 & 59,8 \\
& 32,1 & 48,0 & 60,1 & 20,6 & 45,6 & 57,9 \\
& 33,2 & 45,9 & 60,1 & 21,0 & 44,9 & 60,1 \\
& 32,5 & 48,8 & 59,8 & 19,8 & 43,8 & 60,0 \\
& 31,4 & 46,0 & 58,9 & 18,8 & 41,1 & 60,2 \\
& 31,5 & 47,0 & 58,7 & 19,9 & 44,8 & 59,8 \\
& 31,4 & 49,9 & 58,8 & 18,7 & 42,8 & 57,8 \\
Média & 33,2 & 45,1 & 59,1 & 20,6 & 44,7 & 58,4 \\
D.P. & 33,3 & 47,3 & 60,3 & 20,1 & 45,1 & 58,6 \\
\hline D. & 32,4 & 45,1 & 61,0 & 19,9 & 42,9 & 59,1 \\
& 33,1 & 46,0 & 59,8 & 19,8 & 41,3 & 59,8 \\
& 33,0 & 47,8 & 57,9 & 17,6 & 43,5 & 59,6 \\
& 33,1 & 48,5 & 60,4 & 17,8 & 44,8 & 59,7
\end{tabular}

D.P.: desvio padrão 
observou-se tecido ósseo neoformado disposto em trabéculas delgadas, sem orientação espacial definida e com pouca ou nenhuma conexão com a superfície do osso receptor; no grupo experimento as trabéculas ósseas neoformadas eram longas e finas, orientadas em ângulo reto à superfície femoral e conectadas umas às outras por trabéculas paralelas à superfície do osso receptor.
Com 21 dias, em ambos grupos havia presença de infiltrado inflamatório com poucas células gigantes multinucleadas, trabéculas ósseas densas com aspecto de osso lamelar e fragmentos de matriz óssea bovina envoltos por tecido ósseo neoformado. No grupo controle o canal medular mostrava-se mal definido e com dimensões reduzidas; no grupo experimento houve completa reconstituição do espaço medular (Figura 1, E-F).

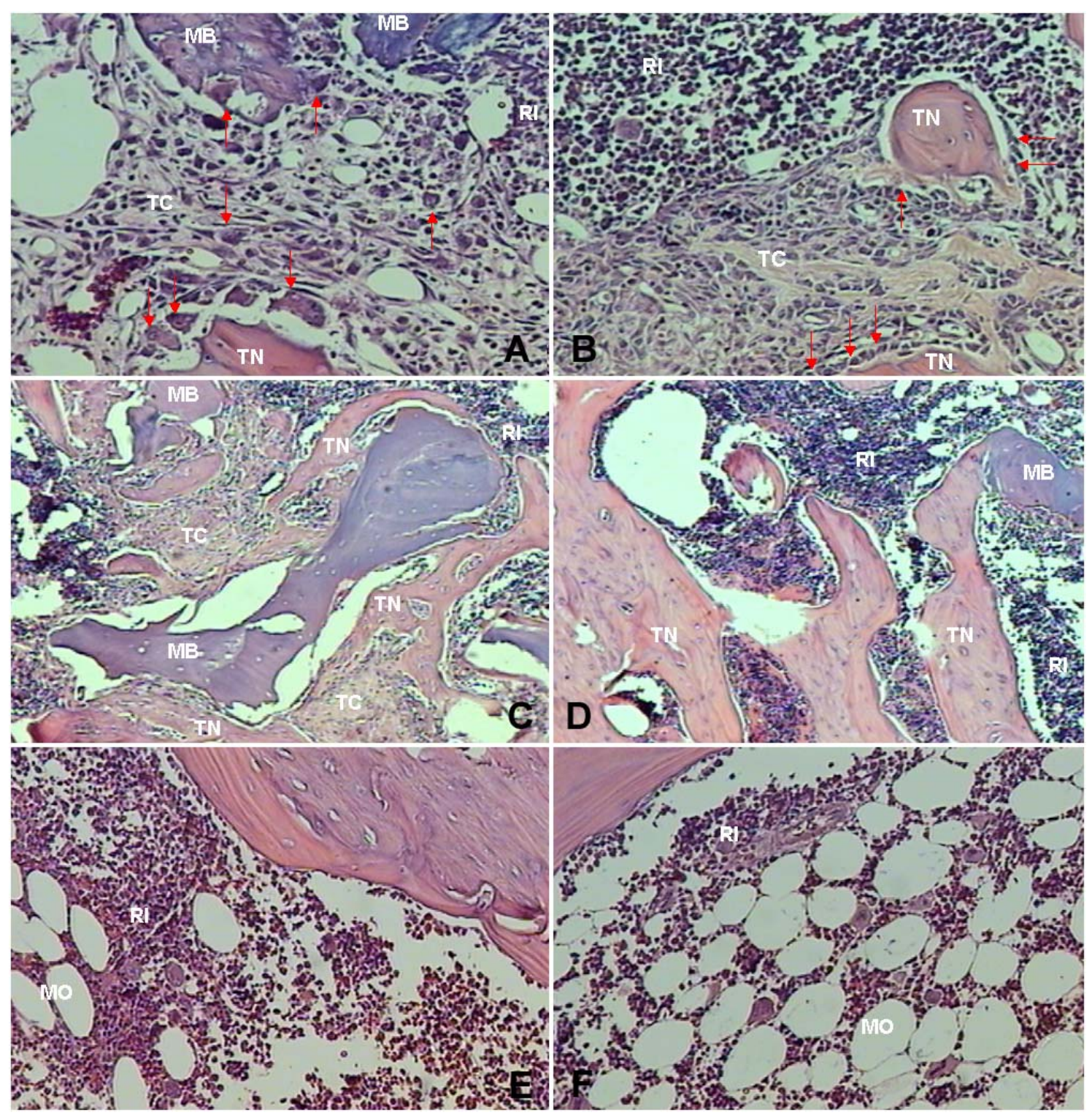

FIGURA 1 - Fotomicrografias da área do defeito padrão (HE-100x).

A: 7 dias de seguimento, sem calcitonina, mostrando fragmentos de matriz óssea bovina (MB), reação inflamatória (RI), tecido conjuntivo (TC), trabéculas ósseas neoformadas (TN) e células gigantes multinucleadas (setas) em contato com a matriz óssea bovina e dispersas no infiltrado inflamatório.

B: 7 dias de seguimento, com calcitonina, mostrando reação inflamatória, tecido conjuntivo rico em osteoblastos (setas) e trabéculas ósseas neoformadas.

C: 14 dias de seguimento, sem calcitonina, mostrando fragmentos de matriz óssea bovina, reação inflamatória, tecido conjuntivo e delgadas trabéculas de osso neoformado.

D: 14 dias de seguimento, com calcitonina, fragmentos de matriz óssea bovina, reação inflamatória, tecido conjuntivo e espessas e bem organizadas trabéculas de osso neoformado.

E: 21 dias de seguimento, sem calcitonina, mostrando formação incompleta da medular óssea e presença de reação inflamatória.

F: 21 dias de seguimento, com calcitonina, mostrando formação completa da medular óssea e presença de reação inflamatória. 
TABELA 3 - Fêmures dos animais dos grupos I e II com respectivos subgrupos A, B e C, segundo a quantificação da reação inflamatória (porcentagem)

\begin{tabular}{|c|c|c|c|c|c|c|}
\hline \multirow[b]{2}{*}{ SUBGRUPO } & \multicolumn{3}{|c|}{ GRUPOI } & \multicolumn{3}{|c|}{ GRUPO II } \\
\hline & A & B & C & A & B & C \\
\hline & 46,3 & 29,6 & 12,1 & 44,8 & 24,6 & 11,2 \\
\hline & 42,4 & 28,9 & 11,6 & 43,8 & 25,9 & 11,3 \\
\hline & 45,0 & 29,3 & 10,5 & 41,6 & 26,0 & 11,5 \\
\hline & 43,8 & 28,4 & 11,3 & 39,8 & 25,1 & 12,0 \\
\hline & 45,9 & 27,8 & 10,6 & 38,4 & 26,3 & 12,3 \\
\hline & 41,8 & 29,1 & 10,6 & 44,5 & 26,5 & 11,0 \\
\hline & 39,8 & 28,2 & 11,5 & 46,1 & 26,1 & 12,4 \\
\hline & 40,8 & 27,3 & 12,3 & 47,2 & 25,4 & 13,5 \\
\hline & 39,9 & 25,6 & 14,0 & 45,6 & 27,1 & 12,3 \\
\hline & 41,2 & 25,8 & 12,4 & 44,3 & 26,9 & 12,5 \\
\hline & 45,6 & 22,6 & 11,5 & 42,4 & 25,8 & 13,0 \\
\hline & 42,6 & 25,1 & 11,6 & 41,8 & 27,2 & 13,1 \\
\hline & 45,8 & 26,4 & 11,5 & 41,8 & 26,8 & 11,0 \\
\hline & 47,0 & 27,1 & 12,0 & 46,9 & 25,4 & 11,3 \\
\hline & 45,6 & 26,0 & 11,6 & 42,3 & 25,5 & 11,2 \\
\hline & 44,6 & 25,6 & 11,2 & 43,8 & 26,1 & 11,4 \\
\hline Média & 43,6 & 27,1 & 11,6 & 43,4 & 26,0 & 11,9 \\
\hline D.P. & 2,41 & 1,89 & 0,85 & 2,47 & 0,74 & 0,81 \\
\hline
\end{tabular}

D.P.: desvio padrão

\section{Discussão}

A correção de defeitos ósseos com perda de substância tem no enxerto ósseo autógeno o padrão ideal, mas sua utilização possui fatores limitantes, como a sisponibilidade em pacientes com baixa reserva de osso autógeno ${ }^{13}$.

A regeneração óssea guiada por biomateriais facilita a formação óssea por proteção contra a invasão de tecidos não-osteogênicos competidores e as matrizes inorgânicas são lentamente reabsorvidas e substituídas por osso neoformado ${ }^{14}$. Entre os biomateriais disponíveis como substitutos ósseos, a matriz óssea bovina desvitalizada foi selecionada neste trabalho experimental, para preenchimento das cavidades ósseas, por ser biocompatível, ter reserva de matéria prima suficiente, ser de baixo custo e fácil manuseio, podendo ser estocada em temperatura ambiente enão exigindo instrumental cirúrgico especial para sua aplicação ${ }^{1,5,15}$.

Como a osteogênese reparadora de defeitos ósseos, com ou sem uso de enxertia óssea, pode ser influenciada por fatores biológicos e físicos, promovendo aceleração ou retardando a reparação óssea, decidiu-se estudar as possíveis ações da calcitonina, em dose única, na integração da matriz óssea bovina desvitalizada em defeitos ósseos femorais provocados operatoriamente, em ratos.

A calcitonina é um hormônio polipeptídico que participa ativamente da homeostase esquelética como regulador do metabolismo mineral e ósseo, interferindo na ação do paratormônio na manutenção da massa óssea ${ }^{8}$.

A experimentação animal e os estudos clínicos mostraram que a calcitonina de salmão é a mais ativa das calcitoninas isoladas e absolutamente isenta de proteínas animais exógenas ${ }^{8}$.

Por ser degradada pelos sucos gástricos, a calcitonina é administrada via subcutânea, retal, endovenosa, intramuscular ou nasal ${ }^{8}$. Nesta pesquisa utilizou-se a calcitonina de salmão, via intramuscular, pela facilidade de aplicação da droga, melhor controle da dosagem e pela dificuldade de aplicação por via venosa ou nasal nos animais da amostra utilizada.

Com relação à dose de calcitonina, há divergências na literatura ${ }^{9,10,11,12}$ para este estudo utilizou-se a dose de 2UI, via intramuscular, que corresponde à dosagem terapêutica em humanos ${ }^{16}$.

Decidiu-se pela utilização da calcitonina, em dose única, no pós-operatório imediato, porque segundo Ito e col..$^{14}$, a estimulação da formação óssea ocorre 
quando a calcitonina é administrada antes do início da osteogênese, provocando um aumento no número de células osteoblásticas. Este aspecto foi observado, com sete dias de seguimento, nos animais tratados com calcitonina, pela presença de uma maior concentração de osteoblastos, alinhados sobre as superfícies do tecido ósseo neoformado, enquanto nos animais não tratados com calcitonina a predominância era de osteoclastos. Estas observações foram similares às relatadas por Ziegler e Delling ${ }^{10}$ e por Mantzavinos e Listgarten ${ }^{17}$.

O rato foi escolhido como modelo animal pela facilidade de obtenção de amostra homogênea e simplicidade de manuseio. O ganho de peso apresentado por todos os animais da amostra $(\mathrm{p}=$ 0,096) demonstra que os procedimentos operatórios realizados, o biomaterial utilizado e a droga injetada não interferem com o desenvolvimento normal do animal no período estudado.

A ausência de calcificações ectópicas na análise macroscópica demonstra que a matriz óssea bovina desvitalizada permite ajuste adequado ao defeito ósseo, sendo contido na cavidade pela cobertura muscular, sem necessidade de fixação adicional.

A identificação visual do defeito na cortical óssea, no período estudado, é explicada pela característica centrípeta da cicatrização de defeitos ósseos, havendo inicialmente a formação e organização do hematoma por tecido de granulação, formação de tecido ósseo de padrão imaturo não lamelar; maturação das trabéculas ósseas, atividade osteoclástica e formação do estroma medular ${ }^{1,5,7}$. Acredita-se que a ausência do acesso operatório cortical femoral tenha características tempo-dependente, ou seja, que o período de seguimento utilizado neste trabalho experimental tenha sido insuficiente para a completa remodelação óssea cortical. Estes resultados foram similares aos relatados por Delling e Glueckselig ${ }^{18} \mathrm{em}$ estudo de regeneração de defeitos corticais em tíbias de ratos.

Para o reparo, a formação óssea depende de adequado suprimento vascular com os osteoblastos exercendo suas atividades nas regiões adjacentes aos vasos sangüíneos, onde a elaboração de tecido ósseo altamente organizado requer uma superfície mecanicamente estável sendo o osso neoformado depositado em uma base sólida ${ }^{19}$. Este aspecto foi demonstrado na análise microscópica onde, em todos os períodos de seguimento, houve neoformação de tecido ósseo, na sua grande maioria, justaposta às paredes do defeito e à superfície da matriz óssea bovina desvitalizada, que se mostrava basófila e com sinais de reabsorção, demonstrando ser a mesma, um arcabouço biológico adequado para a neovascularização e deposição óssea.

Nos animais tratados com calcitonina, o aspecto histológico da área do defeito padrão, com sete dias de seguimento, demonstrou uma maior concentração de osteoblastos e formação de tecido osteóide, com trabéculas ósseas neoformadas exibindo numerosos osteoblastos alinhados em sua periferia; nos animais não tratados, o defeito ósseo mostrava-se preenchido por tecido conjuntivo bem vascularizado, rico em fibroblastos e células gigantes, com menor concentração de osteoblastos.

Nos animais tratados com calcitonina, com quatorze dias de seguimento, as trabéculas ósseas mostraram-se inicialmente longas e finas, orientadas em ângulo reto à superfície femoral e conectadas umas às outras por curtas trabéculas paralelas à superfície do osso, progredindo para trabéculas espessas e bem organizadas, enquanto que nos animais não tratados com calcitonina, a maioria das trabéculas apresentava disposição em mosaico, algumas vezes, formando um ângulo agudo com a superfície do osso. Esta variação de arquitetura provavelmente decorreu de maior estresse resultante da mobilização mais ativa dos membros operados, em função da ação analgésica da calcitonina ${ }^{8}$.

No seguimento de vinte e um dias, houve formação de medular óssea ampla e bem definida nos animais tratados com calcitonina, enquanto que nos animais não tratados, a medular óssea mostrava aspecto indiferenciado e dimensões mais reduzidas. Estes resultados foram semelhantes aos relatados por Pereira e col. ${ }^{19}$ e Sanchez e col. ${ }^{20}$.

A reação inflamatória fisiológica é desencadeada em qualquer situação que exija cicatrização ou haja presença de materiais identificados pelo organismo como corpos estranhos. Na literatura existem relatos ${ }^{1,5,12,17,18}$ da intensa reação inflamatória desencadeada pela presença da matriz óssea bovina desvitalizada e da presença de células gigantes multinucleadas, o que também foi demonstrado neste estudo.

Com sete e quatorze dias houve significância estatística na maior neoformação óssea, nos animais tratados com calcitonina $(Z=4,82$ e $Z=4,43$, 
respectivamente), porém em seguimento de 21 dias, a presença de tecido ósseo neoformado foi semelhante e sem significância estatística em ambos grupos $(Z=0,777)$. Estes resultados foram semelhantes aos relatados por Pereira e $\mathrm{col}^{19}{ }^{19} \mathrm{e}$ Delling e Glueckselig ${ }^{18}$.

Nos resultados da quantificação da reação inflamatória não houve diferença estatisticamente significante entre os animais tratados e os não tratados com calcitonina, nos períodos de seguimento.

O real conceito sobre a atividade da calcitonina no reparo de defeitos ósseos preenchidos com biomaterial inorgânico absorvível ainda é limitado, sendo a comparação com dados da literatura dificultada pela diferença de metodologia, modelo experimental, dose empregada, via e tempo de administração da calcitonina, demandando estudos futuros para melhor conhecimento de sua ação sobre as células constituintes do tecido ósseo.

\section{Conclusão}

A ação da calcitonina faz-se mais evidente nas fases iniciais da osteogênese reparadora, estimulando a neoformação óssea, mas sem provocar diminuição da reação inflamatória, em ratos.

\section{Referências}

1. Figueiredo AS. Estudo morfológico comparativo entre implantes de osso bovino desvitalizado, hidroxiapatita porosa de coral, poliuretana de mamona e enxerto ósseo autógeno, em coelhos [Tese - Doutorado]. Universidade Federal de São Paulo - Escola Paulista de Medicina; 2001.

2. Finkemeier CG. Bone-grafting and bone-graft substitutes. J Bone Joint Surg 2002; 84(3):454-65.

3. Braga FJC, Silva GM, König Jr B. Obtenção de Matriz mineral de osso bovino e a comprovação de sua biocompatibilidade. Rev Bras Cir Protese Implant 1999; 6(4):43-9.

4. Service R.F. Tissue engineers build new bone. Science 2000; 289:1498-500.

5. Sassioto MCP, Massaschi CM, Aydos RD, Silva AR, Takita LC, Figueiredo MJPSS, Bueno TAAO. Estudo morfológico do reparo de defeito ósseo preenchido com enxerto ósseo autógeno ou matriz óssea bovina, em ratos. Ensaios Ci 2003; 7:543-50.

6. Bostrom MPG, Yang X, Koutras IK. Biologics in bone healing. Curr Opin Orthop 2000; 11:403-12.

7. Sedel L. Bone substitutes. Rev Prat 2001; 51(10):1049-51.

8. Azria M. Las calcitoninas. Fisiología y Farmacología. Madrid: Mayo; 1998.

9. Guarniero R, Barros Filho TEP, Tannuri U, Leivas TP,
Negri JH, Prado MP, Etchenehere M, Arruda AAF, Pereira EAR, Cunha MRR, Robazzi PSM. Avaliação da resistência óssea com e sem a administração prévia de calcitonina de salmão em ratos com desnutrição protéica. Acta Ortop Bras 1996; 4(1):23-6.

10. Ziegler R, Delling G. Effect of calcitonin on the regeneration of circumscribed bone defect (bored hole in the rat tibia). Acta Endocr 1972; 69: 497-506.

11. Paavolainen P, Taivainen T, Michelsson JE, Lalla M, Penttinen R. Calcitonin and fracture healing. An experimental study on rats. J Orthop Res 1989; 7(1):1006.

12. Canavero E, Januário AL, Sallum EA, Novaes PD, Nociti Junior FH. Avaliação histométrica da ação local da calcitonina de salmão no processo de reparo ósseo: estudo em ratos. Pesqui Odontol Bras 2000; 14(2):183-7.

13. Boone DW. Complications of iliac crest graft and bone grafting alternatives in foot and ankle surgery. Foot Ankle Clin 2003; 8(1):1-14.

14. Ito N, Yamazaki H, Nakazaki M, Miyahara T, Kozuka H, Sudo H. Response of osteoblastic clonal cell line (MC3T3E1) to [Asu] eel calcitonin at a specific cell density or differentiation stage. Calcif Tissue Int 1987; 40(4):200-5.

15. Burg KJL, Porter S, Kellam JF. Biomaterial developments for bone tissue engineering. Biomaterials 2000; 21:234759.

16. ABIFARMA. Dicionário de especialidades farmacêuticas. São Paulo: Publicações Científicas, 1994/ 5.

17. Mantzavinos Z, Listgarten MA. Thyrocalcitonin stimulated bone formation by local aplication to rat calvaria in vivo. J Periodontol 1970; 41:663-6.

18. Delling G, Glueckselig W. The effect of calcitonin on the regeneration of circumscribed tibia defect and in mineral contents of bonr in the rat. Isr J Med Sci 1971; 7:367-78.

19. Pereira SLS, Toledo S, Okamoto T, Sallum EA, Nociti Júnior FH. Efeito da calcitonina de salmão sobre a cicatrização de defeitos ósseos, estudo radiográfico e histológico em coelhos. Rev Odontol UNESP 1997; 26(2):471-88.

20. Sanches MPR, Marzola C, Taga R. Avaliação microscópica em ratos [Wistar albinus] de implantes de matriz de osso liofilizado “Osseobond” + proteína morfogenética + membrana de osso bovino liofilizado “dentoflex. In: Marzola C. Cirurgia pré-protética. São Paulo: Pancast; 2002. p.203-12.

Correspondência:

Maria Cristina Pita Sassioto

Avenida Joana D’Arc, 954, Bl 34/203

Tel.: (67)387-7513

79070-170 Campo Grande-MS

xxaxxi@brturbo.com

Recebimento: 15/06/2004

Revisão: 26/07/2004

Aprovação:02/09/2004 
Conflito de interesse: nenhum

Fonte de financiamento: nenhuma

\section{Como citar este artigo:}

Sassioto MCP, Inouye CM, Aydos RD, Figueiredo AS, Pontes ERJC, Takita LC. Estudo do reparo ósseo com matriz óssea bovina desvitalizada e calcitonina em ratos. Acta Cir Bras [serial online] 2004 Set-Out. Disponível em URL: http://www.scielo.br/acb [também em CD-ROM].

*Figura colorida disponível em $\underline{\text { www.scielo.br/acb }}$ 